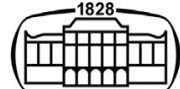

AKADÉMIAI KIADÓ

Journal of Behavioral Addictions

10 (2021) 3, 683-689

DOl:

10.1556/2006.2021.00058

(c) 2021 The Author(s)

\title{
The stock market as a casino: Associations between stock market trading frequency and problem gambling
}

\author{
MORITZ MOSENHAUER ${ }^{1}$, PHILIP W. S. NEWALL ${ }^{2 *}$ (1) and \\ LUKASZ WALASEK ${ }^{3}$ (1)
}

\author{
${ }^{1}$ Management Center Innsbruck, Universitätstrasse 15, Innsbruck 6020, Austria \\ ${ }^{2}$ Experimental Gambling Research Laboratory, School of Health, Medical and Applied Sciences, \\ CQUniversity, 400 Kent St, Sydney, NSW 2000, Australia \\ ${ }^{3}$ Department of Psychology, University of Warwick, Coventry, CV4 7AL, UK
}

Received: February 22, 2021 - Revised manuscript received: June 29, 2021 • Accepted: August 11, 2021

Published online: September 28, 2021

\section{FULL-LENGTH REPORT}

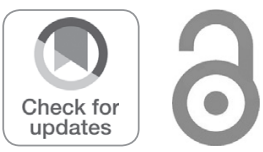

\begin{abstract}
Background and aims: Personal investors decrease their stock market investment returns by trading frequently, which the behavioral finance literature has primarily explained via investors' overconfidence and low levels of financial literacy. This study investigates whether problem gambling can help account for frequent trading in a sample of active gambler/investors, as suggestive of frequent trading being in part driven by a behavioral addiction to gambling-like activities. Methods: A retrospective crosssectional study of 795 US-based participants, who reported both being active gamblers and holding stock market investments. Recollected stock trading activity (typical portfolio size, purchases and sales of stocks) was compared with scores on the Problem Gambling Severity Index, a financial literacy scale, and a measure of overconfidence. Results: Self-reported relative stock portfolio turnover was positively associated with problem gambling scores. This association was robust to controls for financial literacy, overconfidence, and demographics, and occurred equally among investors of all self-reported portfolio sizes. Discussion and conclusions: This study provides support for the hypothesis that behavioral addiction to gambling-like activities is associated with frequent stock market trading. New investment products that increase the ease of trading may therefore be detrimental to some investors.
\end{abstract}

\section{KEYWORDS}

disordered gambling, household finance, overtrading

\section{INTRODUCTION}

'IInvesting is a unique kind of casino-one where you cannot lose in the end, so long as you play only by the rules that put the odds squarely in your favor.' - Benjamin Graham, The Intelligent Investor (2003) p. 36

Investing for retirement and gambling are usually seen as two distinctly different activities. A small number of professional gamblers aside (Sklansky and Malmuth, 1998; Thorp, 1966), gambling is usually seen as an entertainment activity that comes at a price for some, and an addictive and harmful behavior for others (Wardle, Reith, Langham, \& Rogers, 2019). Investing, meanwhile, due to the increasing availability of novel investment products and platforms, and the increasing trend toward defined-contribution retirement systems in many countries, is seen as a necessary part of preparing for retirement. However, there are potential similarities between engagement in the financial markets and gambling. Both activities can provide a wealth of stimuli, underlying information (e.g., stocks returns or the spins on a roulette wheel), and the hope of making money in the face of the risk of loss. 
Although buying stocks and lottery tickets seem distinctly opposite in terms of wealth creation opportunities, some studies have suggested that trading in high-risk stocks tends to decrease when a particularly high lottery jackpot is available, suggesting that some stock buyers may be similarly motivated by the dream of striking it lucky with one clever stock pick (Dorn, Dorn, \& Sengmueller, 2015; Gao \& Lin, 2015; Kumar, 2009). Similar hopes of large gains may also explain an association between problem gambling and cryptocurrency engagement (Mills \& Nower, 2019) - a novel high-risk investment in electronic currencies.

A number of studies have reported that many day traders - those who engage in high-frequency buying and selling stocks on the same day- often seek treatment at gambling treatment clinics (Grall-Bronnec et al., 2017; Granero et al., 2012; Shin, Choi, Ha, Choi, \& Kim, 2015; Team \& Turner, 2011). A qualitative research study has found that online stock traders view trading and gambling as closely related (Dixon, Giroux, Jacques, \& Grégoire, 2018). Meanwhile, studies have linked problem gambling with investments in "high-risk stocks, options, or futures" (Arthur, Delfabbro, \& Williams, 2015, p.40), and with day trading (Arthur \& Delfabbro, 2017). Arthur, Williams, and Delfabbro (2016) provide a recent review of this literature. However, one limitation of this literature is that both day trading and investing in complex financial products such as options could be relatively niche activities: Arthur and Delfabbro (2017), for example, found merely 61 day-traders in their sample of 9,508 southern Australians. It remains to be seen whether problem gambling is associated with frequent trading, even among those who may not qualify as daytraders.

Problem gambling has also been found to be correlated with novel "problem trading" scales, specifically constructed from items across some of the main problem gambling instruments, both in Korea (Youn, Choi, Kim, \& Choi, 2016), and the Netherlands (Cox, Kamolsareeratana, \& Kouwenberg, 2020). Although novel problem trading instruments appear promising (Cox et al., 2020; Youn et al., 2016), the ability of these scales to predict negative outcomes longitudinally still has to be confirmed. Both investing and gambling do, however, have empirically-established patterns of costly behavior, specifically frequent trading (Barber \& Odean, 2000) and problem gambling (Ferris \& Wynne, 2001).

We therefore contribute to this literature by investigating associations between problem gambling and frequent stock market trading via across-sectional study of 795 personal investors from the US. In any cross-sectional study, it is important to check whether any observed associations remain significant when controlling for related constructs which could act as alternative explanation of the effect. Therefore, we use a hierarchical regression approach to see whether the correlation between problem gambling and stock market trading frequency remains significant when adding controls for overconfidence (Statman, Thorley, \& Vorkink, 2006) and financial literacy (Lusardi \& Mitchell, 2014): two established causes of financial mistakes in the behavioral finance literature. It is also important to control for demographic factors relevant to either gambling or investing, in order to see whether the association occurs across investors in general, or only within specific groups. Existing evidence shows that young males with low wealth are most likely to suffer from problematic gambling (Browne et al., 2019). At the same time, young males tend to achieve subpar investment returns (Barber \& Odean, 2001). Our hierarchical approach therefore also adds controls for gender and age to again see if the correlation between problem gambling and stock market trading frequency remains significant in the presence of these variables.

Investing is furthermore an activity which increasingly cuts across different socioeconomic groups. We therefore specify a regression equation that includes a proxy measure of socioeconomic status by controlling for self-reported portfolio value. However, we felt that this was an especially important relationship to explore as wealthier investors, for example, may have access to investment advice and resources not available to less affluent investors. Therefore, we specified an interaction model, to see whether any relationship between problem gambling and stock market trading frequency would differ amongst investors of varying self-reported portfolio values.

Our outcome variable is self-reported relative portfolio turnover, being the fraction of one's average portfolio value that is bought or sold over the course of a year. This variable accounts for differences between investors due to the size of one's portfolio. For example, an investor with trades of $\$ 1,000$ and an average value of $\$ 1,000$ could have the same relative portfolio turnover as an investor with $\$ 100,000$ of each. Results suggest the average stock is now held for less than six months, compared to around seven years in the 1960s (Chatterjee \& Adinarayan, 2020). This is not beneficial for investors as trading imposes costs due to trading fees, bid-ask spreads, taxes, and losses to institutional investors. These losses can add up to $5.9 \%$ for a single trade swapping say a holding of Microsoft stock for Apple stock (Odean, 1999), and it has been suggested that the average investor loses $3.8 \%$ a year due to trading too frequently (Barber, Lee, Liu, \& Odean, 2009). We chose to focus on self-reported relative portfolio turnover instead of reported investment gains or losses, due to potential bias driven by the independent variable of problem gambling; problem gamblers may especially misremember (Toneatto, Blitz-Miller, Calderwood, Dragonetti, \& Tsanos, 1997) or lie about (Ferris \& Wynne, 2001) their gambling returns, and similar results might be expected of their investing returns.

This study therefore investigated the following preregistered hypotheses:

H1 Is the Problem Gambling Severity Index (PGSI; Ferris \& Wynne, 2001) associated with an increased selfreported frequency of relative portfolio turnover?

$\mathrm{H} 2$ Is any hypothesized link in $\mathrm{H} 1$ robust to the addition of controls for measures of overconfidence, (Alpert \& Raiffa, 1982), financial literacy (Fernandes, Lynch, \& Netemeyer, 2014), and age and gender? 
H3 Does further adding a main effect of portfolio value and an interaction effect between PGSI and portfolio value reveal whether the effect of interest from the models specified $\mathrm{H} 2$ depends on the size of the investor's portfolio?

\section{METHOD}

The study was preregistered prior to data collection. Anonymized data, materials and the preregistration document can be accessed from: https://osf.io/prmwn/.

\section{Participants}

Participants were recruited and paid via Prolific Academic. The sample was restricted to individuals who were US residents, had prior experience with gambling, and also had household investments. The household investments filter was necessary, as only people with an investment portfolio could provide meaningful responses to the dependent variable. The gambling experience restriction was added because PGSI scores tend to be highly skewed in the general population, with most people scoring zero, and so this restriction was added so that a more balanced range of PGSI scores might be collected.

A total of 1,042 participants started the survey. Of those, 30 had to be dropped either due to not finishing the survey or revoking consent. Moreover, 127 reported an average portfolio-size of $\$ 0$ and thus were dropped from all analyses as preregistered. The average completion time was approximately $12 \mathrm{~min}$ after dropping outliers beyond the $1^{\text {st }}$ - and $99^{\text {th }}$-percentile (as planned in advance), and participants were paid $\$ 1.25$ each for completing the survey. Thus, taking part in the survey yielded an average payment of $\$ 6.25$ per hour.

Participants answered on average $73 \%$ of the questions on financial literacy correctly, compared to a range of between 56 and $60 \%$ for the original study (Fernandes et al., 2014). Previous studies using Prolific Academic found that US investors answered between 75 and $78 \%$ of these questions correctly, compared to $60 \%$ by US non-investors (Weiss-Cohen, Newall, \& Ayton, 2021). This suggests that the sample collected for the present study was financiallyliterate, as the target population of investors was expected to be.

According to the distribution of PGSI scores, 25.9\% were non-problem gamblers, $26.6 \%$ were low-risk gamblers, $30.8 \%$ were moderate-risk gamblers, and $16.7 \%$ were current problem gamblers.

\section{Materials}

The survey was comprised of four main sections. Participants encountered those sections in a randomised order. The Problem Gambling Severity Index, a nine-item measure of problem gambling for use in community samples (Ferris \& Wynne, 2001), acted as the main independent variable. Second, we included a 13-item scale of financial literacy
(Fernandes et al., 2014). Third, we adapted an overconfidence measure from Alpert and Raiffa (1982). This measure included ten general knowledge questions, such as "What is the air distance from London to Tokyo (in miles)?". Participants were instructed to provide two answers for each question, a low and a high estimate. These answers should be as close as possible to what they believe is the true answer but far enough apart so that they are $90 \%$ sure that the stated interval contains the actual true answer. Participants were instructed not to attempt to look up the correct answers for either the financial literacy or overconfidence measures. Our data suggests that participants genuinely engaged with this task. Only $0.4 \%$ of participants set all intervals correctly (potentially indicating participants looking up correct answers on the internet), and 7.4\% set all intervals incorrectly.

Finally, we asked participants to self-report their past 12month investing activity:

'Have you owned any financial securities (stocks, bonds, mutual funds etc.) during the last twelve months? Include the value of anything held in an investment account or a definedcontribution retirement account.'

Participants who stated that they did not own any financial securities were directed to the end of the survey. The remaining participants were next asked:

'Please provide an estimate of the total value of your financial
portfolio on average on any given day over the past 12
months.

Include the value of any assets held in an investment account or a defined contribution retirement account. Do not include the value of any real estate you may own or any cash in a bank account.

Provide a value that is your best guess in US dollars. Do not enter the dollar sign (\$).

You said on the last page that the total value of your financial portfolio was on average [value entered] on any given day over the past 12 months.

Please provide an estimate of the total value of all trades you made in your financial portfolio over the past 12 months.

Total value of all purchases

Provide a value that is your best guess in US dollars. Do not enter the dollar sign (\$).

Total value of all sales

Provide a value that is your best guess in US dollars. Do not enter the dollar sign (\$).'

\section{Data analysis}

Ordinary Least Squares (OLS) regression was used for all analyses. The main outcome measure was the volume of trades relative to portfolio size, called relative turnover. For this variable, we added the total value of purchases of securities to the total value of sales of securities to obtain a measure of absolute turnover. Dividing this number by the average portfolio size yielded the measure of relative turnover. 
Each item in the PGSI has responses valued from 0 to 3 where increasing numbers represent increased gambling problems, and the index is the sum of these nine questions. For the financial literacy scale we counted the number of correctly answered questions. For the overconfidence measure, we counted how often the correct answer to the general knowledge questions was outside of the stated interval. These were then standardized to range from 0 to 1 . Lastly, we added controls for the age and gender of the participants as drawn from Prolific Academic's demographic information, where the latter is coded as 1 for females and 0 otherwise. The one deviation from the preregistered statistical analysis plan was as follows. The distribution of the dependent variable was observed prior to the running of any analysis, and some outliers were observed, with, for example, one observation of a relative portfolio turnover of 360 , compared to a median of 0.8 . We therefore excluded outliers below the 5\%- and above the 95\%-percentiles from our analysis (dropping 87 observations). Finally, three participants with non-valid responses on the overconfidence measure were also dropped. Therefore, the final sample size was 795 participants. Table 1 shows some descriptive statistics of the main variables of this study.

Table 1. Descriptive statistics

\begin{tabular}{lcc}
\hline & $\begin{array}{c}\text { Mean } \\
(1)\end{array}$ & $\begin{array}{c}\text { Std. Dev. } \\
(2)\end{array}$ \\
\hline Panel A: trading outcomes & & \\
$\quad$ Value purchases & 54,571 & 521,191 \\
Value sales & 47,975 & 374,804 \\
Value portfolio & 137,472 & 682,661 \\
Relative turnover & 0.9765 & 0.8914 \\
Panel B: individual characteristics & & \\
Probl. Gambl. SI & 0.1406 & 0.1707 \\
Financ. Lit. Ind. & 0.7304 & 0.1909 \\
Overconf. Index & 0.6767 & 0.2174 \\
Female dummy & 0.444 & 0.4972 \\
Age & 33.41 & 11.04 \\
\hline
\end{tabular}

Notes: This table provides descriptive statistics in the reduced sample (dropping missing data and outliers) for the study's variables.

\section{Ethics}

The study procedures were carried out in accordance with the Declaration of Helsinki. The Institutional Review Board of the University of Warwick approved the study. All subjects were informed about the study, and all provided informed consent.

\section{RESULTS}

The layered nature of Hypotheses 1-3 meant that we chose to adopt a hierarchical regression approach, with all the results shown in Table 2 using the outcome variable of relative portfolio turnover (value of sales and purchases of securities divided by portfolio value). Column 1 shows the estimate relevant to Hypothesis 1: this regression equation shows the bivariate association between relative portfolio turnover and PGSI as an independent variable. Columns 2 and 3 are relevant to Hypothesis 2, and show what happens to the estimate from Hypothesis 1 when control variables are added first for overconfidence and financial literacy (Column 2), and then also for gender and age (Column 3). Finally, Columns 4 and 5 are relevant to Hypothesis 3. Both of these last two columns add an independent variable for portfolio size and an interaction term between portfolio size and PGSI. Column 4 does this without controls for age and gender, while Column 5 retains age and gender in the regression equation.

The single estimate in Column 1 of Table 2 is statistically significant $(P<0.001)$, and the estimate is positive, revealing support for Hypothesis 1. Since PGSI, Overconfidence, and Financial Literacy measures have been standardized, the estimated coefficient of 1.350 in Column 1 suggests that an increase of one unit in PGSI is associated with an increase in relative turnover of 1.35 .

Since Hypothesis 1 was supported, additional models were run to see if this association remained significant when further controlling for established determinants of gambling and investing behavior. Column 2 adds the measures of Overconfidence and Financial Literacy as additional independent variables, while Column 3 further adds gender and age. In both of these regression equations, the estimate on

Table 2. Results of hierarchical regressions relevant to Hypotheses 1-3

\begin{tabular}{|c|c|c|c|c|c|}
\hline & $\begin{array}{c}(1) \\
\text { Rel.Turn. }\end{array}$ & $\begin{array}{c}(2) \\
\text { Rel.Turn. }\end{array}$ & $\begin{array}{c}\text { (3) } \\
\text { Rel.Turn. }\end{array}$ & $\begin{array}{c}(4) \\
\text { Rel.Turn. }\end{array}$ & $\begin{array}{c}\text { (5) } \\
\text { Rel.Turn. }\end{array}$ \\
\hline PGSI & $1.350(<0.001)$ & $1.005(<0.001)$ & $0.931(<0.001)$ & $1.044(<0.001)$ & $0.990(<0.001)$ \\
\hline Overconf. & & $0.0526(0.692)$ & $0.0787(0.551)$ & $0.0586(0.660)$ & $0.0846(0.524)$ \\
\hline Fin. Lit. & & $-0.958(<0.001)$ & $-0.785(<0.001)$ & $-0.949(<0.001)$ & $-0.790(<0.001)$ \\
\hline Female & & & $0.0427(0.492)$ & & $0.0381(0.540)$ \\
\hline Age & & & $-0.0151(<0.001)$ & & $-0.0153(<0.001)$ \\
\hline Portfolio value & & & & $-1.11 \mathrm{e}-08(0.864)$ & $5.02 \mathrm{e}-08(0.235)$ \\
\hline PGSI Portfolio value & & & & $-0.000000251(0.470)$ & $-0.000000455(0.064)$ \\
\hline$N$ & 795 & 795 & 789 & 795 & 789 \\
\hline
\end{tabular}

Notes: Outliers beyond the 5\%- and 95\%-percentile in the distribution of the dependent variable have been dropped. Each cell shows the estimated coefficient for each independent variable, with the relevant $P$-values shown immediately below in parentheses. PGSI,

Overconfidence, and Financial Literacy scales have been standardized. Six participants had missing demographic data, showing why the sample size drops to 789 in Columns 3 and 5. 
PGSI remains positive and statistically significant $(P<0.001)$. This therefore reveals support for Hypothesis 2. Furthermore, the direction of the association between Overconfidence and Financial Literacy and relative trading frequency were as expected. Estimates for overconfidence were positive, suggesting that increases in overconfidence were associated with higher levels of relative portfolio turnover. Estimates for financial literacy were negative, suggesting that increases in financial literacy were associated with lower levels of relative portfolio turnover. However, of the two, only financial literacy was statistically significant ( $P$-value $<0.001$ across all models).

Hypothesis 3 was not supported, however. The independent variable for portfolio value was not statisticallysignificantly related with relative portfolio turnover in either Column $4(P=0.864)$, or Column $5(P=0.235)$. Furthermore, the interaction term between PGSI and portfolio value was also not statistically significant in either Column 4 ( $P=$ $0.470)$, or Column $5(P=0.064)$. This reveals that the associations between PGSI and relative portfolio turnover occurred equally across investors of all wealth levels.

Barber and Odean (2001) report that male traders have a stronger tendency to trade frequently and, consequently, enjoy lower net returns. They attribute this behavior to potential gender-differences in overconfidence, where men more strongly overestimate their ability to predict future stock price movements. Our exploratory results are inconsistent with this finding. In fact, we find that the average relative turnover is higher for females than for males $(P<0.001)$. However, genderrelated differences in trading outcomes appear to be merely driven by correlated differences in underlying determinants of trading behavior. Contrary again to Barber and Odean (2001), we find that females also tend to be more overconfident than males. Also, men tend to be more financially literate, as well as older. Interestingly, we do not find any gender-related difference in problem gambling severity. Once all these other factors are accounted for, gender-effects on relative portfolio turnover become insignificant $(P \geq 0.492$ in Table 2).

We perform a number of checks in order to ensure robustness of our results. In our main analysis, we drop datapoints with the lowest and highest $5 \%$ of measurements with respect to our dependent variable relative turnover. Conducting the identical analysis without dropping outliers reveals that the two indices on problem gambling severity and financial literacy on which we based our two main findings maintain their direction in all specifications. However, due to the much larger volatility in the extended sample, the robustness of the relationships greatly decreases. Statistical significance at the conventional levels for both variables is now only reached for certain specifications. It should be noted, however, that this extended sample features realisations with measurements of up to 360 in relative turnover while the median lies at 0.8 . These extraordinary realisations may be the result of false statements that are hard to incorporate sensibly into the given linear regression framework.

We also considered winsorizing at the 5\%-thresholds towards both sides of the distribution of the dependent variable as an alternative method of accounting for outliers. Additionally, to ensure that our results are not driven by skewness in the dependent variable, we run the same analysis by taking logarithms of our measure for relative turnover. In both analyses, this paper's proposed main results (confirming Hypothesis 1 and Hypothesis 2) maintain throughout all specifications.

\section{DISCUSSION}

The stock market is a unique kind of casino, which allows the majority of investors to win over time (Graham, 2003). This study contributes to previous research into investing and gambling in two ways. Firstly, previous studies of the link between investing and gambling have sometimes focused on only the minority of investors appearing at gambling clinics (Grall-Bronnec et al., 2017; Granero et al., 2012; Shin et al., 2015; Team \& Turner, 2011), on the activities of a small number of day-traders (Arthur \& Delfabbro, 2017), or on investors' engagement with high-risk investments such as options (Arthur et al., 2015; Williams et al., 2021). This study built on that research by broadening the sample of interest to US investors in general, and by associating problem gambling with perhaps the most prevalent error from the behavioral finance literature: the too frequent trading of stocks (Barber \& Odean, 2000). This study found that problem gambling was associated with a costly investment behavior (trading frequency) even at much lower levels of engagement with investments than has been found in the previous literature. This accords with a recent position in gambling research, that a significant amount of gambling-related harm can occur below the problem gambler risk category (Browne \& Rockloff, 2018). Secondly, as hypothesized, this association remained significant when controlling for overconfidence (Statman et al., 2006) and financial literacy (Fernandes et al., 2014) - two other drivers of suboptimal investing behaviors previously identified in the behavioral finance literature. This study suggests therefore that greater consideration should be given to the hypothesis that a behavioral addiction to gambling-like activities contributes to suboptimal investment behaviors amongst a considerable number of investors in general. Furthermore, the study also suggests that gambling prevalence surveys should also ask about questions related to investing, as one recent Canadian survey has done (Williams et al., 2021).

Previous research has linked frequent trading with overconfidence (Barber \& Odean, 2001). In the present research this link became insignificant once financial literacy was included in the model. This suggests that financial literacy could protect against poor investment choices driven by overconfidence, as a previous study also suggests (Ahmad \& Shah, 2020). This helps support the international evidence base on the importance of financial literacy (Goyal \& Kumar, 2021). Moreover, these findings could also have conceptual links with what has been found previously in gambling. Some investors may overestimate their level of financial literacy (Allgood \& Walstad, 2016), similar to how some gamblers may have false confidence in their understanding of gambling, for example through cognitive biases such as the illusion of control (Leonard, Williams, \& 
McGrath, 2021). Therefore, these results can potentially contribute to an understanding of suboptimal decision making across multiple risky domains.

Previous research has also linked frequent trading and overconfidence with male gender, which the present research did not find (Barber \& Odean, 2001). Previous gambling research has also linked problem gambling and male gender (Afifi, Cox, Martens, Sareen, \& Enns, 2010; Williams et al., 2021), which the present research also did not find. Gender differences in the present study became insignificant once all other variables were controlled for. Future research should explore potential explanations for these disparate results. For example, it could be that gender differences in investment behavior are becoming less innate over time (Chen \& Cheng, 2016), and are instead getting increasingly mediated by differences in behavior and knowledge, which the other variables control for.

This study is subject to the following limitations. The study was limited to participants who were US investors and who had self-reported gambling in their past. The measures of stock market value and trading were based on self-reports, which may be subject to error or bias. Participants were drawn from a crowdsourcing platform, meaning that this was a convenience sample which was not representative of US investors as a whole. There are other potential explanatory variables not considered by this study, since many preferences (e.g. risk taking, impulsivity) are in fact correlated with PGSI (Browne et al., 2019). Future studies could explore this for a fuller profile of problem gambling traits in the context of investing. Although the correlation between trading frequency and problem gambling remained significant when controlling for our measure of overconfidence, other overconfidence measures should also be considered. We measured general overconfidence, whereas overconfidence in one's own financial knowledge may be more relevant (Barber, Huang, Ko, \& Odean, 2020). The study also did not attempt to measure the potential cost from lost financial market portfolio returns that is associated with problem gambling.

Despite these limitations, our results indicate that motivations of individuals to trade frequently may indeed be troublesome. Previous articles (Dorn et al., 2015; Gao \& Lin, 2015) have argued that individuals treat trading securities as an exciting leisure activity. Losses from frequent trading may be thus viewed as a fee for entertainment. Our findings, however, suggest that frequent trading, and thus the associated losses, may be driven in part by a behavioral addiction to gambling-like activities. This study may serve as a step toward further examinations of this association.

Funding declaration: This research was funded by a Research Development Fund awarded to Lukasz Walasek from the University of Warwick.

Authors' contributions: Study concept and design: MM and $\mathrm{PN}$, analysis and interpretation of data: MM and PN, statistical analysis: MM, obtained funding: LW, study supervision: $\mathrm{PN}$ and $\mathrm{LW}$.
Conflict of interest: Philip Newall is a member of the Advisory Board for Safer Gambling - an advisory group of the Gambling Commission in Great Britain, and in 2020 was a special advisor to the House of Lords Select Committee Enquiry on the Social and Economic Impact of the Gambling Industry. In the last three years Philip Newall has received research funding from Clean Up Gambling, and has contributed to research projects funded by GambleAware, Gambling Research Australia, NSW Responsible Gambling Fund, and the Victorian Responsible Gambling Foundation. In 2019 Philip Newall received travel and accommodation funding from the Spanish Federation of Rehabilitated Gamblers, and in 2020 received an open access fee grant from Gambling Research Exchange Ontario. The other authors have no interests to declare.

\section{REFERENCES}

Afifi, T. O., Cox, B. J., Martens, P. J., Sareen, J., \& Enns, M. W. (2010). Demographic and social variables associated with problem gambling among men and women in Canada. Psychiatry Research, 178(2), 395-400. https://doi.org/10.1016/j.psychres.2009.10.003.

Ahmad, M., \& Shah, S. Z. A. (2020). Overconfidence heuristicdriven bias in investment decision-making and performance: Mediating effects of risk perception and moderating effects of financial literacy. Journal of Economic and Administrative Sciences. https://doi.org/10.1108/JEAS-07-2020-0116.

Allgood, S., \& Walstad, W. B. (2016). The effects of perceived and actual financial literacy on financial behaviors. Economic Inquiry, 54(1), 675-697. https://doi.org/10.1111/ecin.12255.

Alpert, M., \& Raiffa, H. (1982). A progress report on the training of probability assessors. In D. Kahneman, P. Slovic, \& A. Tversky (Eds.), Judgment under uncertainty: Heuristics and biases (pp. 294-305). Cambridge: Cambridge University Press.

Arthur, J. N., \& Delfabbro, P. (2017). Day traders in south Australia: Similarities and differences with traditional gamblers. Journal of Gambling Studies, 33(3), 855-866. https://doi.org/10. 1007/s10899-016-9659-x.

Arthur, J. N., Delfabbro, P., \& Williams, R. J. (2015). Is there a relationship between participation in gambling activities and participation in high-risk stock trading? Journal of Gambling Business \& Economics, 9(3), 34-53. https://doi.org/10.1016/j. psychres.2009.10.003;10.5750/jgbe.v9i3.1034.

Arthur, J. N., Williams, R. J., \& Delfabbro, P. H. (2016). The conceptual and empirical relationship between gambling, investing, and speculation. Journal of Behavioral Addictions, 5(4), 580-591. https://doi.org/10.1556/2006.5.2016.084.

Barber, B. M., Huang, X., Ko, K. J., \& Odean, T. (2020). Leveraging overconfidence. Available at SSRN 3445660.

Barber, B. M., Lee, Y., Liu, Y., \& Odean, T. (2009). Just how much do individual investors lose by trading? The Review of Financial Studies, 22(2), 609-632. https://doi.org/10.1093/rfs/hhn046.

Barber, B. M., \& Odean, T. (2000). Trading is hazardous to your wealth: The common stock investment performance of individual investors. The Journal of Finance, 55(2), 773-806. https://doi.org/10.1111/0022-1082.00226. 
Barber, B. M., \& Odean, T. (2001). Boys will be boys: Gender, overconfidence, and common stock investment. Quarterly Journal of Economics, 116(1), 261-292. https://doi.org/10.1162/ 003355301556400.

Browne, M., Hing, N., Rockloff, M., Russell, A. M., Greer, N., Nicoll, F., \& Smith, G. (2019). A multivariate evaluation of 25 proximal and distal risk-factors for gambling-related harm. Journal of Clinical Medicine, 8(4), 509. https://doi.org/10.3390/ jcm8040509.

Browne, M., \& Rockloff, M. J. (2018). Prevalence of gamblingrelated harm provides evidence for the prevention paradox. Journal of Behavioral Addictions, 7(2), 410-422. https://doi.org/ 10.1556/2006.7.2018.41.

Chatterjee, S., \& Adinarayan, T. (2020). Buy, sell, repeat! no room for 'hold' in whipsawing markets. Retrieved from https://www. reuters.com/article/us-health-coronavirus-short-termism-analidUSKBN24Z0XZ.

Chen, A., \& Cheng, T. Y. (2016). Are men more overconfident than women? Evidence from the taiwan futures market. European Financial Management Association, 1-38.

Cox, R., Kamolsareeratana, A., \& Kouwenberg, R. (2020). Compulsive gambling in the financial markets: Evidence from two investor surveys. Journal of Banking \& Finance, 111, 105709. https://doi.org/10.1016/j.jbankfin.2019.105709.

Dixon, M. R., Giroux, I., Jacques, C., \& Grégoire, P. (2018). What characterizes excessive online stock trading? A qualitative study. Journal of Gambling Issues, 38. https://doi.org/10.4309/ jgi.2018.38.2.

Dorn, A. J., Dorn, D., \& Sengmueller, P. (2015). Trading as gambling. Management Science, 61(10), 2376-2393. https://doi. org/10.1287/mnsc.2014.1979.

Fernandes, D., Lynch, J. G., \& Netemeyer, R. G. (2014). Financial literacy, financial education, and downstream financial behaviors. Management Science, 60(8), 1861-1883. https://doi.org/10. 1287/mnsc.2013.1849.

Ferris, J., \& Wynne, H. J. (2001). The Canadian problem gambling index: Final report. Ottawa, ON: Canadian Centre on Substance Abuse.

Gao, X., \& Lin, T. (2015). Do individual investors treat trading as a fun and exciting gambling activity? Evidence from repeated natural experiments. The Review of Financial Studies, 28(7), 2128-2166. https://doi.org/10.1093/rfs/hhu075.

Goyal, K., \& Kumar, S. (2021). Financial literacy: A systematic review and bibliometric analysis. International Journal of Consumer Studies, 45(1), 80-105. https://doi.org/10.1111/ijcs.12605.

Graham, B. (2003). The intelligent investor (Revised ed.). New York: Harper Business.

Grall-Bronnec, M., Sauvaget, A., Boutin, C., Bulteau, S., JiménezMurcia, S., Fernández-Aranda, F., ... Caillon, J. (2017). Excessive trading, a gambling disorder in its own right? A case study on a French disordered gamblers cohort. Addictive Behaviors, 64, 340-348. https://doi.org/10.1016/j.addbeh.2015.12.006.

Granero, R., Tárrega, S., Fernández-Aranda, F., Aymamí, N., Gómez-Peña, M., Moragas, L., ... Menchón, J. M. (2012).
Gambling on the stock market: An unexplored issue. Comprehensive Psychiatry, 53(6), 666-673. https://doi.org/10.1016/j. comppsych.2011.12.004.

Kumar, A. (2009). Who gambles in the stock market? The Journal of Finance, 64(4), 1889-1933. https://doi.org/10.1111/j.15406261.2009.01483.x.

Leonard, C. A., Williams, R. J., \& McGrath, D. S. (2021). Gambling fallacies: Predicting problem gambling in a national sample. Psychology of Addictive Behaviors. https://doi.org/10.1037/ adb0000673.

Lusardi, A., \& Mitchell, O. S. (2014). The economic importance of financial literacy: Theory and evidence. Journal of Economic Literature, 52(1), 5-44. https://doi.org/10.1257/jel.52.1.5.

Mills, D. J., \& Nower, L. (2019). Preliminary findings on cryptocurrency trading among regular gamblers: A new risk for problem gambling? Addictive Behaviors, 92, 136-140. https:// doi.org/10.1016/j.addbeh.2019.01.005.

Odean, T. (1999). Do investors trade too much? American Economic Review, 89(5), 1279-1298. https://doi.org/10.1257/aer.89. 5.1279 .

Shin, Y., Choi, S., Ha, J., Choi, J., \& Kim, D. (2015). Gambling disorder in financial markets: Clinical and treatment-related features. Journal of Behavioral Addictions, 4(4), 244-249. https://doi.org/10.1556/2006.4.2015.032.

Sklansky, D., \& Malmuth, M. (1998). Gambling for a living: How to make \$100,000 a year. Las Vegas, Nevada: Two Plus Two Publishing.

Statman, M., Thorley, S., \& Vorkink, K. (2006). Investor overconfidence and trading volume. The Review of Financial Studies, 19(4), 1531-1565. https://doi.org/10.2139/ssrn.168472.

Team, D., \& Turner, N. E. (2011). The addictiveness of online brokerage services: A first person account. Journal of Gambling Issues, 25, 113-129. https://doi.org/10.4309/jgi.2011.25.9.

Thorp, E. O. (1966). Beat the dealer. Random.

Toneatto, T., Blitz-Miller, T., Calderwood, K., Dragonetti, R., \& Tsanos, A. (1997). Cognitive distortions in heavy gambling. Journal of Gambling Studies, 13(3), 253-266. https://doi.org/10. 1023/a:1024983300428.

Wardle, H., Reith, G., Langham, E., \& Rogers, R. D. (2019). Gambling and public health: We need policy action to prevent harm. Bmj, 365. https://doi.org/10.1136/bmj.11807.

Weiss-Cohen, L., Newall, P. W. S., \& Ayton, P. (2021). Persistence is futile: Chasing of past performance in repeated investment choices. Journal of Experimental Psychology: Applied, https:// doi.org/10.1037/xap0000358.

Williams, R. J., Leonard, C. A., Belanger, Y. D., Christensen, D. R., El-Guebaly, N., Hodgins, D. C., .. Stevens, R. M. (2021). Predictors of gambling and problem gambling in Canada. Canadian Journal of Public Health, 112, 521-529. https://doi.org/ 10.17269/s41997-020-00443-x.

Youn, H., Choi, J., Kim, D., \& Choi, S. (2016). Development and validation of a stock addiction inventory (SAI). Annals of General Psychiatry, 15(1), 16. https://doi.org/10.1186/s12991016-0105-3. 